\title{
Prevalence of criminal convictions in Norwegian adult ADHD outpatients and associations with ADHD symptom severity and emotional dysregulation
}

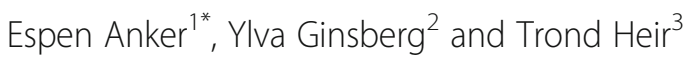

\begin{abstract}
Objectives: Attention deficit hyperactivity disorder (ADHD) often co-occurs with antisocial behaviour. Several studies have shown high rates of ADHD among prisoners. However, the prevalence of crime among individuals with ADHD is less known. The aim of the present study was to estimate the prevalence of lifetime criminal conviction (CC) in a clinical sample of adults with ADHD, and the associations with the severity of ADHD and emotional dysregulation (ED).
\end{abstract}

Methods: Patients were admitted to a private psychiatric outpatient clinic in Oslo between 2014 and 2018. Of the 656 patients diagnosed with ADHD, 629 (95.9\%) agreed to participate in the study. CC was determined based on self-reporting of the lifetime history of criminal behaviour. ADHD was diagnosed according to the DSM-5 criteria, and ADHD severity was measured using the Adult ADHD Self-Report Scale (ASRS). ED was assessed by the eightitem version of Barkley's Current Behaviour Scale - Self-Report (CBS-SR).

Results: The prevalence of self-reported CC in this clinical sample was $11.7 \%$ among women and $24.5 \%$ among men. CC was associated with hyperactive-impulsive severity $(p<0.001)$ and $\operatorname{ED}(p=0.006)$.

Conclusions: The prevalence of self-reported lifetime criminal conviction was high for both genders. CC was associated with symptom severity of hyperactivity-impulsivity and emotional dysregulation. The findings suggest the need for greater research efforts on the avoidance of criminal activity in people with ADHD and targeted intervention for ADHD treatment and CC prevention.

Keywords: ADHD severity, Offending, Deficient emotional self-regulation, Emotional dysregulation, Criminal conviction, Antisocial behaviour, Substance use disorder

\section{Introduction}

Attention deficit hyperactivity disorder (ADHD) often co-occurs with antisocial behaviour [1, 2]. Several studies have estimated that the prevalence of ADHD among male inmates ranges from 15 to 50\% [3-7]. Metaanalyses have indicated an average prevalence of

\footnotetext{
* Correspondence: espen.anker@online.no

${ }^{1}$ Oslo ADHD Clinic, Kirkeveien 64B, 0366 Oslo, Norway

Full list of author information is available at the end of the article
}

approximately $25 \%$ in male inmates $[8,9]$, and even as high as $40 \%$ in female inmates [10]. These rates far exceed the estimated $3-5 \%$ prevalence rates of ADHD in the general adult population $[11,12]$.

Longitudinal studies have found that children with ADHD have a high risk of later antisocial activity and criminal conviction $(\mathrm{CC})$ in adulthood [13, 14]. The long-term outcomes of Danish children with ADHD indicated that nearly half had a history of CC in adulthood

(C) The Author(s). 2021 Open Access This article is licensed under a Creative Commons Attribution 4.0 International License, which permits use, sharing, adaptation, distribution and reproduction in any medium or format, as long as you give appropriate credit to the original author(s) and the source, provide a link to the Creative Commons licence, and indicate if changes were made. The images or other third party material in this article are included in the article's Creative Commons licence, unless indicated otherwise in a credit line to the material. If material is not included in the article's Creative Commons licence and your intended use is not permitted by statutory regulation or exceeds the permitted use, you will need to obtain permission directly from the copyright holder. To view a copy of this licence, visit http://creativecommons.org/licenses/by/4.0/ The Creative Commons Public Domain Dedication waiver (http://creativecommons.org/publicdomain/zero/1.0/) applies to the data made available in this article, unless otherwise stated in a credit line to the data. 
[15]. Other studies found girls with ADHD to have seven times higher odds of having an incarceration record than non-ADHD girls, while boys with ADHD had two times higher odds [16]. A Swedish national register-based study found that $15.4 \%$ of women and $36.6 \%$ of men with ADHD were convicted of any crime [17]. There is a lack of studies comparing $\mathrm{CC}$ and no-CC as an outcome for both genders [18].

Knowledge of the prevalence of CC in an ADHD outpatient clinic may be helpful for health authorities to plan appropriate services and help clinicians plan specialized treatments for adult ADHD. Measurements of the prevalence of CC may also contribute to the elucidation of possible causes and the achievement of treatment.

Several studies have indicated that $\mathrm{CC}$ and antisocial behaviour are correlated with the severity of ADHD [2, 19-23], and we aimed to confirm this in our study.

Previous studies have found general adjustment problems to be linked to antisocial behaviour in adults with ADHD [24]. Antisocial behaviour is largely mediated by emotional lability and anger problems [25]. Excessive and inappropriate emotional expressions, irritability, and temper outbursts may be recorded as clinical expressions of emotional dysregulation (ED) [26, 27]. ED is a common feature in ADHD, even though it is not part of the criteria of the disorder [28-37]. ED, irrespective of ADHD, is associated with aggressive and violent criminality [38]. ED in adults is clinically similar to oppositional defiant disorder in youth, which has been linked to antisocial behaviour $[39,40]$. Whether the severity of ED is associated with CC has yet to be shown.

The aims of the present study were to estimate the prevalence of $\mathrm{CC}$ in a clinical sample of outpatients with ADHD and to examine its associations with ADHD symptom severity and ED.

\section{Method}

This was an observational cross-sectional clinical study.

\section{Participants}

The study population consisted of adult outpatients aged 18 to 65 who were not imprisoned who fulfilled the diagnostic criteria for a diagnosis of ADHD according to the Diagnostic and Statistical Manual of Mental Disorders, Fifth Edition (DSM-5) [41]. Patients were admitted to a private outpatient non-inmate psychiatric clinic in Oslo, Norway, specializing in the clinical assessment and treatment of adults with ADHD.

Recruitment was conducted between 2014 and 2018. ADHD was assessed using DIVA 2.0 the semi-structured Diagnostic Interview for Adult ADHD, second edition [42]. The assessment was performed by a psychiatrist for all patients included in the study. DIVA 2.0 is a reliable tool for assessing and diagnosing adult ADHD [43]. During the study period, 656 of the assessed patients fulfilled the diagnostic criteria for ADHD and were invited to participate in the study, of whom $65 \%$ were self-referred and $35 \%$ were referred by healthcare practitioners. None of the participants were using prescribed stimulant medication at the time of assessment. There were no exclusion criteria.

Of the 656 patients (351 men and 305 women) with ADHD, 629 (95.9\%) gave written informed consent to participate in the study. The study was approved by the Regional Medical Ethics Committee, South-East Norway, 2015/426. Assessments were carried out in accordance with ethical standards, and the principals of the Declaration of Helsinki.

\section{Measures}

The age of the participants was recorded as their respective numbers of lived years when entering the study. Gender was recorded as 'woman' or 'man' based on information revealed by the participant. Sociodemographic information was collected as follows: Participant was married or cohabitating. If a participant was living with children inclusive partial custody, but not even though having children somewhere else. Educational level was categorized based on the number of years in education: 12 years or less, $13-15$ years, or more than 15 years. Work participation was defined as 'yes' if work was reported as the main source of income.

Criminal conviction (CC) was defined as being convicted by the court of any crime under Norwegian law. $\mathrm{CC}$ was recorded as positive when participants selfreported $\mathrm{CC}$ in response to the following question: 'Have you ever been in prison or been convicted for any crime?'. We also recorded which crime they were convicted of.

ADHD symptom severity was measured by the Adult ADHD Self-Report Scale (ASRS) Symptom Check List, v1.1 [44, 45] The ASRS is a reliable and valid screening instrument for evaluating ADHD in adults [46]. The 18item version yields a score ranging from 0 to 72 points. We recorded scores of the subscales of the ASRS questionnaire, i.e., inattentive items (items $1-4$ and 7-11) and hyperactivity - impulsivity items (items 5, 6, and 12-18) separately [47].

Emotion dysregulation covers a large variety of emotion dysregulated responses as overwhelming sadness, anxiety, fear, suicidal actions, plural emotional outbursts, and is also linked to several other diagnoses as depression and anxiety (Dvir et al. 2014 [48]), PTSD and personality disorders (Ford \& Cortious 2014 [49]), brain injury (Fisher et al. 2015 [50]) or dementia (Ismail et al. 2018 [51]). 
Emotion dysregulation in ADHD could alternatively have been assessed by the Impulsivity/Emotional Lability scale from the Conners' Adult ADHD Rating Scales (CAARS) (Conners et al. 1999 [52]) a 12-item subscale which assesses temper, irritability, stress intolerance and labile mood, but in our paper the definition of emotional dysregulation (ED) was narrowed down to measure explosive anger, temper, or irritability according to Russell Barkley [53]. ED was assessed by using eight relevant items from the larger Current Behaviour Scale - Self Report, known as the Deficient Emotional Self-Regulation (DESR) questionnaire [32, 34, 53, 54]. The eight items were as follows: 1: Quick to get angry or become upset; 2: Easily frustrated; 3: Overreact emotionally; 4: Easily excited by activities going on around me; 5: Lose my temper; 6: Argue with others; 7: Am touchy or easily annoyed by others; and 8: Am angry or resentful. The items were marked by participant as never or rarely (0), sometimes (1), often (2) or very often (3). This yielded a total ED score ranging from 0 to 24 .

Alcohol and drug use disorders were diagnosed using a module of the Mini International Neuropsychiatric Interview (M.I.N.I.), Norwegian Translation Version 6.0.0, according to the Diagnostic and Statistical Manual of Mental Disorders, Fourth Edition (DSM-IV) criteria $[55,56]$. Dependence and abuse were merged into 'use' disorder (as in M.I.N.I. version 7.0/DSM-5), and questions were asked regarding both the last 12-months and lifetime prevalence.

\section{Statistical analysis}

Numbers with percent proportions (\%) are reported for all categorical variables. Means with standard deviations (SD) are given for continuous variables. We used chisquare $\left(x^{2}\right)$ tests to compare categorical variables and independent sample T-tests to compare continuous variables. We used logistic regression analyses to examine the associations between $\mathrm{CC}$ as the outcome variable and age, gender, ADHD symptom severity and ED as the independent variables. To avoid bias in the regression analysis we have decided not to control for probable intermediate variables (or a proxy for an intermediate variable) in the causal pathway between ADHD severity or ED and criminal behaviour (Rothman \& Greenland 1998 [57], Gilthorpe et al. 2015 [58], Schisterman et al. 2009 [59]). For example, we have previously published results from the same study sample showing that ADHD severity and ED are associated with alcohol and drug use disorders (Anker et al. 2020 [60]). Both ADHD and ED are early acquired and stable features of a person's emotional and behaviour reaction patterns less influenced by external circumstances (DSM-5, Eisenberg et al.2010 [61]) and can be interpreted as causal in these relationships. Also, it is well known that alcohol and drug use are strong risk factors for criminal behaviour (Dowden \& Brown 2002 [62]). Thus, alcohol and drug use disorders appear to be intermediate variables in the causal pathway between ADHD or ED and criminal behaviour, or they may be a proxy for an intermediate variable in the causal pathway, such as a high-risk social environment. The same argument applies to several variables listed in Table 1, such as education, family relationships and work. Intermediate variables (or a proxy for an intermediate variable), if controlled in an analysis, would usually bias results towards the null, which in the literature is described as a form of overadjustment that should be avoided (Rothman \& Greenland 1998 [57], Gilthorpe et al. 2015 [58], Schisterman et al. 2009 [59]).

All tests were two-tailed, and differences were considered significant if $p<0.05$. There were no missing data. All statistical analyses were performed using the software package IBM 2016 SPSS version 22 [63]. We used Cronbach's alpha statistic to assess the internal consistency reliability of the eight items from the DESR scale. Cronbach's alpha for the eight scale items in our sample was 0.86 indicating high internal consistency.

\section{Results}

Table 1 shows participants with and without a history of criminal conviction (CC). Those with a history of $\mathrm{CC}$ were older, were more often men, had a lower educational level, were less involved in family life and work, and had a higher risk of a history of alcohol or drug use disorders than those without a history of CC.

The prevalence of $\mathrm{CC}$ was $11.7 \%(n=34)$ in women and $24.5 \%(n=83)$ in men.

Among women $(n=290)$, the most common conviction was for selling or possessing drugs $(n=18 ; 6.2 \%)$, followed by violence, $(n=6 ; 2.1 \%)$, traffic crime $(n=6$; $2.1 \%)$, theft $(n=2 ; 0.7 \%)$, and mixed or multiple convictions $(\mathrm{n}=2 ; 0.7 \%)$.

Among men $(n=339)$, the most common conviction was for selling or possessing drugs $(n=32 ; 9.4 \%)$, followed by violence, $(n=24 ; 7.1 \%)$, traffic crime $(n=14$; $4.1 \%)$, theft $(n=5 ; 1.5 \%)$, and mixed or multiple convictions $(n=8 ; 2.4 \%)$.

Hyperactive-impulsive symptom severity and ED were higher in patients who had a history of CC (Table 1).

Table 2 shows associations between criminal conviction (CC) as the outcome variable and age, gender, ADHD symptom severity and emotional dysregulation (ED) as independent variables. Higher levels of hyperactivity-impulsivity symptoms and ED were significantly associated with CC bivariate as well as in multivariate logistic regression model adjusted for age and gender.

There were no significant interactions among age, gender, hyperactive-impulsive symptom severity and ED. 
Table 1 Demographics and clinical features in a sample of adult ADHD patients with and without a history of criminal conviction. Participants were recruited in an outpatient psychiatric clinic specialized in examination and treatment of ADHD

\begin{tabular}{|c|c|c|c|c|}
\hline & $\begin{array}{l}\text { Total sample } \\
n=629\end{array}$ & Criminal Conviction $n=117$ & $\begin{array}{l}\text { No-Criminal Conviction } \\
n=512\end{array}$ & $p$-value \\
\hline Age, mean yrs. (SD) & $36.7(11.4)$ & $39.8(10.0)$ & $35.9(11.6)$ & 0.020 \\
\hline Gender: Women, n (\%) & $290(46.1)$ & $34(29.1)$ & $256(50.0)$ & $<0.001$ \\
\hline Men, n (\%) & $339(53.9)$ & $83(70.9)$ & $256(50.0)$ & \\
\hline Years of education: $\leq 12$ : (\%) & $321(51.0)$ & 92 (78.6) & $229(44.7)$ & $<0.001$ \\
\hline 13-15: (\%) & $248(39.4)$ & $24(20.5)$ & $224(43.8)$ & \\
\hline$>15:(\%)$ & $60(9.5)$ & $1(0.9)$ & $59(11.5)$ & \\
\hline Married or cohabitant, n (\%) & $270(42.9)$ & $38(32.5)$ & $232(45.3)$ & 0.014 \\
\hline Living with children, n (\%) & $248(39.4)$ & $30(25.6)$ & $218(42.8)$ & 0.003 \\
\hline Work participation, n (\%) & $370(58.8)$ & $49(41.9)$ & $321(62.7)$ & $<0.001$ \\
\hline Alcohol use disorder lifetime, n (\%) & 73 (11.6) & $29(24.8)$ & $44(8.6)$ & $<0.001$ \\
\hline Drug use disorder lifetime, n (\%) & $165(26.2)$ & $81(69.2)$ & $84(16.4)$ & $<0.001$ \\
\hline Inattentiveness, mean (SD) & $27.4(4.7)$ & $27.9(5.1)$ & $27.3(4.6)$ & 0.036 \\
\hline Hyperactivity-Impulsivity, mean (SD) & $23.9(6.6)$ & $26.7(5.8)$ & $23.3(6.6)$ & $<0.001$ \\
\hline Emotional Dysregulation, mean (SD) & $12.1(5.6)$ & $14.0(5.6)$ & $11.8(5.5)$ & $<0.001$ \\
\hline
\end{tabular}

$p$-values are due to comparison of ADHD patients with and without a history of criminal conviction (chi-square or t-test)

\section{Discussion}

The study revealed a high incidence of crime among adult ADHD patients. The 11.7 and $24.5 \%$ life-time prevalence rates of criminal conviction (CC) in female and male ADHD patients respectively, were considerable higher than the correspondingly 1 and $5 \%$ rates for women and men in the general Norwegian population [64]. High risk of crime in people with ADHD is also known from other Scandinavian countries with relatively low incidences of crime in the general population $[17,65]$.

The two or threefold higher risk of $\mathrm{CC}$ among men versus women is in line with other studies of ADHD patients $[7,16,65]$. The ratio is similar to that in the general population $[64,66]$, which indicates that gender differences are not affected by ADHD.

The finding that $\mathrm{CC}$ was associated with the severity of hyperactive-impulsive symptoms is in line with several studies that have shown associations between the severity of ADHD symptoms and different aspects of antisocial behaviour [25, 67-71]. This finding is also consistent with longitudinal studies of children with ADHD showing that the severity of hyperactivityimpulsivity symptoms was associated with later occurrence of $C C[64,72]$. It is likely that restlessness and impulsivity symptoms may result in less well-considered behaviour that may also include violation of the law. It is also possible that criminal acts by people with hyperactive-impulsive symptoms are more due to sensation and novelty seeking $[73,74]$ and less planned and proactive and that people with ADHD are therefore more likely to be convicted [75].

With this aspect in mind, it seems meaningful to address the severity of ADHD as emphasized in the DSM5 [41] as opposed to categorizing ADHD by sub-type as suggested in the DSM-IV [76]. The strong association between $\mathrm{CC}$ and hyperactive-impulsive severity also underlines the importance of treating ADHD as a

Table 2 Associations between criminal conviction (CC) as the outcome variable and age, gender, ADHD symptom severity and emotional dysregulation (ED) as independent variables in a clinical sample of adult females $(n=290)$ and males $(n=339)$ with ADHD

\begin{tabular}{|c|c|c|c|c|c|c|}
\hline & \multicolumn{3}{|c|}{ Unadjusted } & \multicolumn{3}{|c|}{ Adjusted } \\
\hline & OR & $95 \% \mathrm{Cl}$ & p-value & OR & $95 \% \mathrm{Cl}$ & p-value \\
\hline Age (increase in 10 years) & 1.34 & $1.13-1.60$ & 0.001 & 1.32 & $1.10-1.59$ & 0.003 \\
\hline Gender (Men v. Women) & 2.44 & $1.58-.77$ & $<0.001$ & 3.38 & $2.12-5.39$ & $<0.001$ \\
\hline \multicolumn{7}{|l|}{ ADHD symptom severity } \\
\hline Inattentiveness & 1.03 & $0.98-1.07$ & 0.28 & 0.96 & $0.91-1.02$ & 0.17 \\
\hline Hyperactivity-Impulsivity & 1.09 & $1.05-1.12$ & $<0.001$ & 1.09 & $1.04-1.13$ & $<0.001$ \\
\hline Emotional dysregulation & 1.08 & $1.04-1.12$ & $<0.001$ & 1.07 & $1.02-1.12$ & 0.006 \\
\hline
\end{tabular}

Results are given as odds ratios (ORs) with $95 \%$ confidence intervals $(95 \% \mathrm{Cl}$ ) in bivariate (unadjusted) and multivariate (adjusted) logistic regression models 
dimensional diagnosis and expecting more antisocial behaviour in patients presenting with high levels of hyperactive-impulsive symptoms.

The concept of emotional dysregulation (ED) has different aspects, with both bottom-up strong emotional responses and top-down poorer regulation of emotions. The DESR questionnaire is mostly focused on bottomup emotionality, which has been understood as ED. In our sample, CC was associated with the severity of ED, independent of hyperactive-impulsive severity. We suggest that knowledge on ED does add significantly to the understanding of $\mathrm{CC}$ in people with ADHD, First, ED is a common feature of ADHD, even though it is not part of the diagnostic criteria [28-37, 77]. Second, ED contributes significantly to general impairments in patients with ADHD [78] and has an independent effect on general social problems associated with ADHD [34, 79]. Third, aggression in childhood has been found to predict criminality later in life [72], and personality traits of negative emotionality have been linked to criminal activity [80]. Adding ED severity to the concept of ADHD is in line with Reimherr et al., who emphasize a two-factor solution for ADHD subgroups, with a presentation consisting solely of inattention and a more comprehensive hyperactivity-impulsivity-emotional dysregulation presentation [81].

We found a strong relationship between all background variables and CC. The association between low education and CC is notable since people with ADHD have lower levels of education than the general population [82-84]. Additionally, drug use disorder was correlated with $\mathrm{CC}$, which is worth noting since ADHD patients have higher incidences of drug use than the general population $[25,60,65,85,86]$.

The relationship between crime and substance use disorders may be due to several mechanisms. It is reasonable that substance use and addiction can lead to crime. On the other hand, criminal activity can provide closer contact with intoxicants and drug environments. In addition, there may be common underlying factors that increase the risk of both substance use and crime. The fact that we exclusively had lifetime prevalence for both substance use and CC, and lacked hypotheses of causeeffect, led us not to adjust for substance use in the regression model.

Early identification of ADHD and disruptive behaviour, with subsequent multimodal interventions might reduce the risk of a criminal trajectory. Supporting people with ADHD in attaining higher education and work and avoiding drugs is probably also a good approach to prevent CC.

There are some methodological limitations to consider in this study. CC was measured based on self-report, which may have resulted in under-reporting. Patients attending a private clinic that is not governmentally funded may not be representative of patients with ADHD in general. They may have a higher socioeconomic status and be less impaired than patients in public outpatient clinics or prison inmates. Additionally, the prevalence rates of criminality and morbidity in this population may not be representative of those of the total ADHD patient population. We assume that differences in sample selection may primarily affect the prevalence rates and, to a lesser extent, their associations [87, 88]. The associations with CC should therefore be more generalizable.

The cross-sectional observational design limited the interpretation of causal relationships. We assume ADHD and ED are traits that develop in childhood before the criminal minimum age, which is 15 years in Norway, which may therefore indicate the direction of causality.

\section{Conclusion}

In this clinical sample the prevalence of criminal conviction (CC) was high for both genders compared to the prevalence rates reported in the general population. CC was associated with the severity of hyperactivityimpulsivity, as well as emotional dysregulation, which indicates that knowledge on both features contributes to the understanding of CC in ADHD.

\section{Clinical implication}

Criminal behaviour is common in adults with ADHD. The findings call for research efforts to prevent criminal activity in people with ADHD. The association of higher severity of hyperactivity-impulsivity symptoms and emotional dysregulation with $\mathrm{CC}$ suggests that clinical manifestations should be treated carefully. Early identification as well as biological- and psychological approaches in the prevention and treatment of ADHD and externalizing behaviour should be performed early in childhood and followed up in adulthood by professionals with specific knowledge of treatment and behavioural interactions with the environment. Furthermore, targeted interventions should focus on the preventive effect of academic achievement and higher education for adolescents with ADHD, which could be crucial in avoiding illegal drug use, antisocial behaviour, and criminal activity.

\section{Abbreviations}

ADHD: Attention Deficit Hyperactivity Disorder; ED: Emotional Dysregulation; MINI: Mini International Neuropsychiatric Interview; ASRS: Adult ADHD SelfReport Scale.; CC: Criminal Conviction

\section{Acknowledgements}

We would like to thank Bothild Bendiksen, Susan Young and Gisli Gudjonsson for valuable input on the content. 


\section{Authors' contributions}

EA and TH designed the study. EA collected and analysed the data. All the authors participated actively in the writing of the manuscript. All authors approved the final draft.

\section{Funding}

This work was economically supported by NevSom, Oslo University Hospital, grant number 51379. The funder had no other role in the study or writing the manuscript.

\section{Availability of data and materials}

Data were collected from a private psychiatric outpatient ward in Oslo. Public availability of the data would compromise privacy of the respondents. According to approval from the Norwegian Regional Committee for Medical and Health Research Ethics, the data must be stored properly in line with the Norwegian Law of Privacy Protection. However, anonymized data are freely available to interested researchers upon request, pending ethical approval from the ethics committee. Interested researchers can contact project leader Espen Anker (espen.anker@online.no) with requests for the data.

\section{Declarations}

We confirm that all methods were performed in accordance with relevant guidelines and regulations.

\section{Ethics approval and consent to participate}

The study was approved by the Regional Medical Ethics Committee, SouthEast D, Norway, 2015/426. Written consent to participate was obtained from all participants.

\section{Consent for publication}

Not applicable.

\section{Competing interests}

EA has received speaker honoraria from Shire. TH report no competing interest. YG has received personal fees and non-financial support from Medscape, non-financial support from Shire, and personal fees from Studentlitteratur, all outside the submitted work.

\section{Author details}

'Oslo ADHD Clinic, Kirkeveien 64B, 0366 Oslo, Norway. ${ }^{2}$ Centre for Psychiatry Research, Department of Clinical Neuroscience, Karolinska Institutet \& Stockholm Health Care Services, Stockholm, Sweden. ${ }^{3}$ University of Oslo, Institute of Clinical Medicine, Oslo, Norway.

\section{Received: 11 September 2020 Accepted: 19 April 2021}

\section{Published online: 03 May 2021}

\section{References}

1. Sourander A, Elonheimo H, Niemela S, Nuutila A-M, Helenius H, Sillanmaki L, et al. Childhood predictors of male criminality: a prospective populationbased follow-up study from age 8 to late adolescence. J Am Acad Child Adolesc Psychiatry. 2006;45(5):578Y586. PMID: 16670652. https://doi.org/10.1 097/01.chi0000205699.58626.b5.

2. Mohr-Jensen C, Steinhausen H-C. A meta-analysis and systematic review of the risks associated with childhood attention-deficit hyperactivity disorder on long-term outcome of arrests, convictions, and incarcerations. Clin Psychol Rev. 2016;48:32-42. https://doi.org/10.1016/j.cpr.2016.05.002.

3. Rösler M, Retz W, Retz-Junginger P, Hengesch G, Schneider M, Supprian T, et al. (2004). Prevalence of attention deficit-/hyperactivity disorder (ADHD) and comorbid disorders in young male prison inmates. Eur Arch Psychiatry Clin Neurosci. 2004;254(6):365-71. https://doi.org/10.1 007/s00406-004-0516-z.

4. Einarsson E, Sigurdsson JF, Gudjonsson GH, Newton AK, Bragason OO (2009). Screening for attention-deficit hyperactivity disorder and co-morbid mental disorders among prison inmates. Nord J Psychiatry. 2009;63(5):361-7. 19247871. https://doi.org/10.1080/08039480902759184.

5. Ginsberg Y, Hirvikoski T, Lindefors N. Attention deficit hyperactivity disorder (ADHD) among longer-term prison inmates is a prevalent, persistent and disabling disorder. BMC Psychiatry. 2010;10:112. https://doi.org/10.1186/14 71-244X-10-112.
6. Usher AM, Stewart LA, Wilton G. Attention deficit hyperactivity disorder in a Canadian prison population. Int J Law Psychiatry. 2013;36(3-4):311-5. https://doi.org/10.1016/j.ijp.2013.04.005.

7. Knecht C, de Alvaro R, Martinez-Raga J, Balanza-Martinez V. Attention-deficit hyperactivity disorder (ADHD), substance use disorders, and criminality: a difficult problem with complex solutions. Int J Adolesc Med Health. 2015; 27(2):163-75. https://doi.org/10.1515/ijamh-2015-5007.

8. Young S, Moss D, Sedgwick O, Fridman M, Hodgkins P. A meta-analysis of the prevalence of attention deficit hyperactivity disorder in incarcerated populations. Psychol Med. 2015;45(2):247-58. https://doi.org/10.1017/500332 91714000762

9. Baggio S, Fructuoso A, Guimaraes M, Fois E, Golay D, Heller P, et al. Prevalence of attention deficit hyperactivity disorder in detention settings: a systematic review and meta-analysis. Front Psychiatry. 2018;9:331. https:// doi.org/10.3389/fpsyt.2018.00331.

10. Faroog R, Emerson LM, Keoghan S, Adamou M. (2016). Prevalence of adult ADHD in an all-female prison unit. ADHD Attention Deficit and Hyperactivity Disorders. 2016;8(2):113-9. https://doi.org/10.1007/s12402-0150186-X.

11. Fayyad J, De Graaf R, Kessler R, Alonso J, Angermeyer M, Demyttenaere K, et al. Cross-national prevalence and correlates of adult attention-deficit hyperactivity disorder. Br J Psychiatry. 2007;190(5):402-9. https://doi.org/1 0.1192/bjp.bp.106.034389.

12. Kessler RC, Adler L, Barkley R, Biederman J, Conners CK, Demler O, et al. The prevalence and correlates of adult ADHD in the United States: results from the National Comorbidity Survey Replication. Am J Psychiatry. 2006;163(4): 716-23. 16585449. https://doi.org/10.1176/ajp.2006.163.4.716.

13. Fletcher J, Wolfe B. Long-term consequences of childhood ADHD on criminal activities. J Ment Health Policy Econ. 2009;12(3):119-38.

14. Barkley RA, Fischer A, Smallish L, Fletcher K. (2004) Young adult follow-up of hyperactive children: antisocial activities and drug use. J Child Psychol Psychiatry. 2004 Feb;45(2):195-211. https://doi.org/10.1111/j.1469-7610.2004. 00214.x.

15. Dalsgaard S, Mortensen PB, Frydenberg M, Thomsen PH. Long-term criminal outcome of children with attention deficit hyperactivity disorder. Criminal Behavior Mental Health. 2013;23(2):-98. https://doi.org/10.1002/cbm.1860.

16. Silva D, Colvin L, Glauert R, Bower C. Contact with the juvenile justice system in children treated with stimulant medication for attention deficit hyperactivity disorder: a population study. Lancet Psychiatry. 2014;1(4):27885. https://doi.org/10.1016/S2215-0366(14)70302-5.

17. Lichtenstein P, Halldner L, Zetterqvist J, Sjölander A, Serlachius E, Fazel S, et al. Medication for attention deficit-hyperactivity disorder and criminality. N Engl J Med. 2012;367(21):2006-14. 23171097. https://doi.org/10.1056/ NEJMoa1203241.

18. Retz W, Ginsberg Y, Turner D, Barra S, Retz-Junginger P, Larsson $H$, et al. Attention-Deficit/Hyperactivity Disorder (ADHD), antisociality and delinquent behavior over the lifespan. Neurosci Biobehav Rev. 2021:236-48. https://doi. org/10.1016/j.neubiorev.2020.11.025.

19. Young S, Thome J. (2011) ADHD and offenders. World J Biol Psychiatry. 2011;12(Suppl 1):124-8. https://doi.org/10.3109/15622975.2011.600319.

20. Young S, Wells J, Gudjonsson GH. Predictors of offending among prisoners: the role of attention-deficit hyperactivity disorder and substance use. J Psychopharmacol. 2011;25(11):1524-32. https://doi.org/10.1177/026988111 0370502.

21. Mordre M, Groholt B, Kjelsberg E, Sandstad B, Myhre AM. The impact of $\mathrm{ADHD}$ and conduct disorder in childhood on adult delinquency: A 30 years follow-up study using official crime records. BMC Psychiatry. 2011;11:57. https://doi.org/10.1186/1471-244X-11-57.

22. Unnever JD, Cornell DG. (2003). Bullying, self-control, and ADHD. Journal of interpersonal violence. 2003;18(2):129-47. https://doi.org/10.1177/08862 60502238731

23. Du Rietz E, Kuja-Halkola R, Brikell I, Jangmo A, Sariaslan A, Lichtenstein P, et al. (2017). Predictive validity of parent-and self-rated ADHD symptoms in adolescence on adverse socioeconomic and health outcomes. Eur Child Adolesc Psychiatry. 2017;26(7):857-67. https://doi.org/10.1007/s00787-0170957-3.

24. Young S, Gudjonsson GH. (2006) ADHD symptomatology and its relationship with emotional, social and delinquency problems. Psychol Crime Law. 2006;12(5):463-71. https://doi.org/10.1080/10683160500151183.

25. Gudjonsson GH, Sigurdsson JF, Sigfusdottir ID, Young S. A national epidemiological study of offending and its relationship with ADHD 
symptoms and associated risk factors. J Atten Disord. 2014;18(1):3-13. https://doi.org/10.1177/1087054712437584.

26. Shaw P, Stringaris A, Nigg J, Leibenluft E. Emotion dysregulation in attention deficit hyperactivity disorder. Am J Psychiatry. 2014;171(3):276-93. https:// doi.org/10.1176/appi.ajp.2013.13070966.

27. Stringaris A. Irritability in children and adolescents: a challenge for the DSM 5. Eur Child Adolec Psychiatry. 2011;20:61-6. https://doi.org/10.1007/s00787010-0150-4.

28. Aldao A, Gee DG, De Los RA, Seager I. Emotion regulation as a transdiagnostic factor in the development of internalizing and externalizing psychopathology: Current and future directions. Dev Psychopathol. 2016; 28(4pt1):927-46. https://doi.org/10.1017/S0954579416000638.

29. Shaw P, Stringaris A, Nigg J, Leibenluft E. Emotion dysregulation in attention deficit hyperactivity disorder. Am J Psychiatr. 2014;171(3):276-93. 24480998. https://doi.org/10.1176/appi.ajp.2013.13070966.

30. Connor DF, Steeber J, McBurnett K. (2010) a review of attention- deficit/ hyperactivity disorder complicated by symptoms of oppositional defiant disorder or conduct disorder. J Dev Behav Pediatr. 2010;31(5):427-40. 2053 5081. https://doi.org/10.1097/DBP.0b013e3181e121bd.

31. Landaas ET, Halmøy A, Oedegaard KJ, Fasmer OB, Haavik J. (2012). The impact of cyclothymic temperament in adult ADHD. J Affect Disord. 2012; 142(1-3):241-7. https://doi.org/10.1016/j.jad.2012.04.034.

32. Barkley RA, Murphy KR, Robison RJ, Reimherr FW, Marchant BK, Kondo D, et al. Deficient emotional self-regulation in adults with attention deficit hyperactive disorder (ADHD): the relative contribution of emotional impulsiveness and ADHD symptoms to adaptive impairment in major life activities. J ADHD Related Disorders. 2010;1 (4):5-28. https://doi.org/10.1 521/adhd.2010.18.4.1

33. Surman $C B$, Biederman J, Spencer $T$, Yorks D, Miller CA, Petty $C R$, et al. Deficient emotional self-regulation and adult attention deficit hyperactivity disorder: a family risk analysis. Am J Psychiatry. 2011;168(6):617-23. https:// doi.org/10.1176/appi.ajp.2010.10081172.

34. Surman CB, Biederman J, Spencer T, Miller CA, McDermott KM, Faraone SV Understanding deficient emotional self-regulation in adults with attention deficit hyperactivity disorder: a controlled study. Atten Defic Hyperact Disord. 2013;5(3):273-81. https://doi.org/10.1007/s12402-012-0100-8.

35. Retz W, Stieglitz RD, Corbisiero S, Retz-Junginger P, Rösler M. Emotional dysregulation in adult ADHD: what is the empirical evidence? Expert Rev Neurother. 2012;12(10):1241-51. https://doi.org/10.1586/ern.12.109.

36. Corbisiero S, Mörstedt B, Bitto H, Stieglitz RD. Emotional Dysregulation in adults with attention-deficit/hyperactivity disorder-validity, predictability, severity, and comorbidity. J Clin Psychol. 2017;73(1):99-112. https://doi.org/1 $0.1002 / j \mathrm{jl}$. 22317 .

37. Hirsch O, Chavanon M, Reichmann E, Christiansen H. Emotional dysregulation is a primary symptom in adult Attention-Deficit / Hyperactivity Disorder (ADHD). J Affective Disorders. 2018;232(2018):41-7. https://doi.org/10.1016/j.jad.2018.02.007.

38. Garofalo C, Velotti P. Negative emotionality and aggression in violent offenders: the moderating role of emotion dysregulation. J Crim Just. 2017; 51:9-16. https://doi.org/10.1016/j.jcrimjus.2017.05.015.

39. Aebi M, Barra S, Bessler C, Steinhausen HC, Walitza S, Plattner B. Oppositional defiant disorder dimensions and subtypes among detained male adolescent offenders. J Child Psychol Psychiatry. 2016;57(6):729-36. 26493948. https://doi.org/10.1111/jcpp.12473.

40. Pardini DA, Fite PJ. Symptoms of conduct disorder, oppositional defiant disorder, attention-deficit/hyperactivity disorder, and callous-unemotional traits as unique predictors of psychosocial maladjustment in boys: advancing an evidence base for DSM-V. J Am Acad Child Adolesc Psychiatry. 2010;49(11):1134-44. 20970701. https://doi.org/10.1016/j.jaac.201 0.07.010.

41. APA, American Psychiatric Association. Diagnostic and statistical manual of mental disorders (DSM-5); 2013. https://doi.org/10.1176/appi.books. 9780890425596.x00.

42. Kooij JJS, Francken MH. Diagnostic interview for ADHD in adults 2.0 (DIVA 2. 0). Adult ADHD. 2010:33-99. https://doi.org/10.1007/978-1-4471-4138-9_3.

43. Ramos-Quiroga JA, Nasillo V, Richarte V, Corrales M, Palma F, Ibáñez P, et al. Criteria and concurrent validity of DIVA 2.0: a semi-structured diagnostic interview for adult ADHD. J Atten Disord. 2019;23(10):1126-35. https://doi. org/10.1177/1087054716646451.

44. Adler LA, Kessler RC, Spencer T. Adult ADHD self-report scale-v1. 1 (ASRS-v1. 1) symptom checklist. New York: World Health Organization; 2003.
45. Kessler RC, Adler L, Ames M, Demler O, Faraone S, Hiripi EV, et al. The World Health Organization adult ADHD self-report scale (ASRS): a short screening scale for use in the general population. Psychol Med. 2005;35(2):245-56. https://doi.org/10.1017/s0033291704002892.

46. Silverstein MJ, Alperin S, Faraone SV, Kessler RC, Adler LA. Test-retest reliability of the adult ADHD self-report scale (ASRS) v1.1 screener in nonADHD controls from a primary care physician practice. Family Pract. 2017; 2017:cmx115. https://doi.org/10.1093/fampra/cmx115.

47. Fredriksen M, Dahl AA, Martinsen EW, Klungsøyr O, Haavik J, Peleikis DE. Effectiveness of one-year pharmacological treatment of adult attentiondeficit/hyperactivity disorder (ADHD): an open-label prospective study of time in treatment, dose, side-effects and comorbidity. Eur Neuropsychopharmacol. 2014;24:1873-84. https://doi.org/10.1016/j. euroneuro.2014.09.013

48. Dvir Y, Ford JD, Hill M, Frazier JA. Childhood maltreatment, emotional dysregulation, and psychiatric comorbidities. Harvard Rev Psychiatry. 2014; 22(3):149-61. https://doi.org/10.1097/HRP.0000000000000014.

49. Ford JD, Courtois CA. Complex PTSD, affect dysregulation, and borderline personality disorder. Borderline Personality Disorder and Emotion Dysregulation. 2014;1 (1):1-17. https://doi.org/10.1186/2051-6673-1-9.

50. Fisher AC, Rushby JA, McDonald S, Parks N, Piguet O. Neurophysiological correlates of dysregulated emotional arousal in severe traumatic brain injury. Clin Neurophysiol. 2015;126(2):314-24. https://doi.org/10.1016/j. clinph.2014.05.033.

51. Ismail Z, Gatchel J, Bateman DR, Barcelos-Ferreira R, Cantillon M, Jaeger J, et al. Affective and emotional dysregulation as pre-dementia risk markers: exploring the mild behavioral impairment symptoms of depression, anxiety, irritability, and euphoria. Int Psychogeriatr. 2018;30(2):185-96. https://doi. org/10.1017/S1041610217001880.

52. Conners CK, Erhardt D, Epstein JN, Parker JDA, Sitarenios G, Sparrow E. Self-ratings of ADHD symptoms in adults I: factor structure and normative data. J Atten Disord. 1999;3(3):141-51. https://doi.org/10.1007/978-0-387-79948-3_1278.

53. Barkley RA. Behavioral inhibition, sustained attention, and executive functions: constructing a unifying theory of ADHD. Psychol Bull. 1997;121(1): 65-94. https://doi.org/10.1037/0033-2909.121.1.65.

54. Biederman J, Spencer TJ, Petty C, Hyder LL, O'Connor KB, Surman CBH, et al. Longitudinal course of deficient emotional self-regulation $C B C L$ profile in youth with ADHD: prospective controlled study. Neuropsychiatr Dis Treat. 2012;8:267-76. https://doi.org/10.2147/NDT.S29670.

55. Sheehan $D V$, Lecrubier $Y$, Sheehan $K H$, Amorim $P$, Janavs J, Weiller $E$, et al. The validity of the MINI international neuropsychiatric interview (MINI) according to the SCID-P and its reliability. Eur Psychiatry. 1997;12:232-41. https://doi.org/10.1016/S0924-9338(97)83297-X.

56. Sheehan DV, Lecrubier Y, Sheehan KH, et al. The Mini-international neuropsychiatric interview (M.I.N.I.): the development and validation of a structured diagnostic psychiatric interview for DSM-IV and ICD-10. J Clin Psychiatry. 1998:59(Suppl 20):22-33. https://doi.org/10.1037/t18597-000.

57. Rothman K, Greenland S. Modern Epidemiology. 2nd ed. Philadelphia: Lippincott-Raven; 1998. Epidemiology, Vol. 9, No. 3 (May, 1998). p. 333-7.

58. Gilthorpe MS, Jiang T, Tilling K, Ellison GT, Baxter PD. Common Statistical Errors: Over-Adjustment for Confounders and Mediators in Lifecourse Research. Int J Epidemiol. 2015;44(suppl_1):i36-7. https://doi.org/10.1093/ije/dyv097.126.

59. Schisterman EF, Cole SR, Platt RW. Overadjustment bias and unnecessary adjustment in epidemiologic studies. Epidemiology. 2009;20(4):488-95. https://doi.org/10.1097/EDE.0b013e3181a819a1.

60. Anker E, Haavik J, Heir T. Alcohol and drug use disorders in adult attentiondeficit/hyperactivity disorder: prevalence and associations with attentiondeficit/hyperactivity disorder symptom severity and emotional dysregulation. World J Psychiatr. 2020;10(9) 0000-0000 URL: https://www.wjgnet.com/ 22203206/full/v10/i9/0000.Htm. https://doi.org/10.5498/wjp.v10.19.0000.

61. Eisenberg N, Spinrad TL, Eggum ND. Emotion-related self-regulation and its relation to children's maladjustment. Annu Rev Clin Psychol. 2010;6(1):495525. https://doi.org/10.1146/annurev.clinpsy.121208.131208.

62. Dowden C, Brown SL. The role of substance abuse factors in predicting recidivism: a meta-analysis. Psychol Crime Law. 2002;8(3):243-64. https://doi. org/10.1080/10683160208401818.

63. IBM Corp. (2013). IBM SPSS statistics for windows, version 22.0. Armonk: IBM Corp. DOl: https://doi.org/10.4135/9781526435439.

64. Skardhamar T. Lifetime conviction risk - a synthetic cohort approach. J Scand Stud Criminol Crime Prev. 2014;15(1):96-101. https://doi.org/10.1 080/14043858.2014.883175 
65. Dalsgaard S, Mortensen PB, Frydenberg M, Thomsen PH. ADHD, stimulant treatment in childhood and subsequent substance abuse in adulthood - a naturalistic long-term follow-up study. Addict Behav. 2014;39(1):325-8. https://doi.org/10.1016/j.addbeh.2013.09.002.

66. Walker JT, Maddan S. Understanding statistics for the social sciences, criminal justice, and criminology. Jones \& Bartlett Publishers; 2016. p. 99. ISBN 1449634036. Retrieved August 7, 2016

67. Gudjonsson GH, Sigurdsson JF, Adalsteinsson TF, Young S. The relationship between ADHD symptoms, mood instability, and self-reported offending. Atten Disord. 2013;17(4):339-46. https://doi.org/10.1177/1087054711429791.

68. Gudjonsson GH, Sigurdsson JF, Sigfusdottir ID, Asgeirsdottir BB, González RA, Young S. A national epidemiological study investigating risk factors for police interrogation and false confession among juveniles and young persons. Soc Psychiatry Psychiatr Epidemiol. 2016;51(3):359-67. 26537245. https://doi.org/10.1007/s00127-015-1145-8.

69. Gudjonsson GH, Gonzalez R, Young S. The risk of making a false confession: the role of developmental disorders, conduct disorder, psychiatric symptoms, and compliance. J Atten Disord. 2019;25(5):715-23. https://doi. org/10.1177/1087054719833169.

70. González RA, Gudjonsson GH, Wells J, Young S. The role of emotional distress and ADHD on institutional behavioral disturbance and recidivism among offenders. J Attention Disorder. 2016;20:368-78. https://doi.org/10.11 77/1087054713493322

71. Storebø OJ, Rasmussen PD, Simonsen E. Association between insecure attachment and ADHD: environmental mediating factors. J Attention Disorders. 2016;20(2):187-96. https://doi.org/10.1177/1087054713501079.

72. Pingault J-B, Côté SM, Lacourse E, Galéra C, Vitaro F, Tremblay RE. Childhood Hyperactivity, Physical Aggression and Criminality: A 19-Year Prospective Population-Based Study. PLOS. 2013;8(5):e62594 PMID: 23658752. https://doi. org/10.1371/journal.pone.0062594.

73. Donfrancesco R, Di Trani M, Porfirio MC, Giana G, Miano S, Andriola E. Might the temperament be a bias in clinical study on attention-deficit hyperactivity disorder (ADHD)?: novelty seeking dimension as a core feature of ADHD. Psychiatry Res. 2015;227(2-3):333-8. https://doi.org/10.1016/j. psychres.2015.02.014.

74. Mann FD, Engelhardt L, Briley DA, Grotzinger AD, Patterson MW, Tackett $J$, et al. Sensation seeking and impulsive traits as personality endophenotypes for antisocial behavior: evidence from two independent samples. Personal Individ Differ. 2017;105:30-9. https://doi.org/10.1016/j.paid.2016.09.018.

75. Young S. In: Fitzgerald M, Bellgrove M, Gill M, editors. Forensic aspects of ADHD. Handbook of attention deficit hyperactivity disorder. Chichester: Wiley; 2007. p. 91-108

76. Bell CC. DSM-IV: diagnostic and statistical manual of mental disorders. Jama. 1994;272(10):828-9. https://doi.org/10.1001/jama.1994.03520100096046.

77. Barkley RA, Fischer M. The unique contribution of emotional impulsiveness to impairment in major life activities in hyperactive children as adults. J Am Acad Child Adolesc Psychiatry. 2010;49(5):503-13. https://doi.org/10.1097/ 00004583-201005000-00011.

78. Faraone SV, Rostain AL, Blader J, Busch B, Childress AC, Connor DF, et al Practitioner Review: Emotional dysregulation in attention-deficit/ hyperactivity disorder - implications for clinical recognition and intervention. J Child Psychol Psychiatry. 2018, 2018. PMID: 29624671. https:// doi.org/10.1111/jcpp.12899 Practitioner Review: Emotional dysregulation in attention-deficit/hyperactivity disorder - implications for clinical recognition and intervention.

79. Musser ED, Galloway-Long HS, Frick PJ, Nigg JT. Emotion regulation and heterogeneity in attention-deficit/hyperactivity disorder. J Am Acad Child Adolesc Psychiatry. 2013;52(2):163-171.e2. https://doi.org/10.1016/j.jaac.2 012.11.009.

80. Krueger RF, Schmutte PS, Caspi A, Moffitt TE, Campbell K, Silva PA Personality traits are linked to crime among men and women: evidence from a birth cohort. J Abnorm Psychol. 1994;103(2):328-38. https://doi.org/1 0.1037/0021-843X.103.2.328.

81. Reimherr FW, Roesler M, Marchant BK, Gift TE, Retz W, Philipp-Wiegmann F, et al. Types of adult attention-deficit/hyperactivity disorder: a replication analysis. J Clin Psychiatry. 2020;81(2):0-0. https://doi.org/10.4088/JCP.19m13 077.

82. Ebejer JL, Medland SE, van der Werf J, Gondro C, Henders AK, Lynskey M, et al. Attention Deficit Hyperactivity Disorder in Australian Adults: Prevalence, Persistence, Conduct Problems and Disadvantage. Plos one. 2012;7(10):e47404. https://doi.org/10.1371/journal.pone.0047404.
83. Küpper T, Haavik J, Drexler H, Ramos-Quiroga JA, Wermelskirchen D, Prutz C, et al. The negative impact of attention-deficit/hyperactivity disorder on occupational health in adults and adolescents. Int Archiv Occup Environ Health. 2012;85(8):837-47. https://doi.org/10.1007/s00420-012-0794-0.

84. Barkley RA, Fischer M, Smallish L, MAK F. Young Adult Outcome of Hyperactive Children: Adaptive Functioning in Major Life Activities. J Am Acad Child Adolesc Psychiatry. 2006;45(2):192-202. https://doi.org/10.1097/ 01.chi.0000189134.97436.e2.

85. Von Polier GG, Vloet TD. Herpertz-Dahlmann B (2012). ADHD and delinquency - a developmental perspective. Behav Sci Law. 2012;30(2):12139. https://doi.org/10.1002/bsl.2005.

86. Crunelle CL, Van Den Brink W, Moggi F, Konstenius M, Franck J, Levin FR, et al. (2018) international consensus statement on screening, diagnosis and treatment of substance use disorder patients with comorbid attention deficit/hyperactivity disorder. Eur Addict Res. 2018;24(1):43-51. https://doi. org/10.1159/000487767.

87. Nohr EA, Olsen J. Commentary: Epidemiologists have debated representativeness for more than 40 years - has the time come to move on? Int J Epidemiol. 2013;42(4):1016-7. https://doi.org/10.1093/ije/dyt102.

88. Rothman KJ, Gallacher JEJ, Hatch EE. Why representativeness should be avoided. Int J Epidemiol. 2013;42:1012-4. https://doi.org/10.1093/ije/dys223.

\section{Publisher's Note}

Springer Nature remains neutral with regard to jurisdictional claims in published maps and institutional affiliations.
Ready to submit your research? Choose BMC and benefit from:

- fast, convenient online submission

- thorough peer review by experienced researchers in your field

- rapid publication on acceptance

- support for research data, including large and complex data types

- gold Open Access which fosters wider collaboration and increased citations

- maximum visibility for your research: over $100 \mathrm{M}$ website views per year

At BMC, research is always in progress.

Learn more biomedcentral.com/submissions 